\title{
Expanding the potentialities of standard dilution analysis: Determination of ethanol in gasoline by Raman spectroscopy
}

\author{
Felipe M. Fortunato $^{\mathrm{a}}$, Alan L. Vieira ${ }^{\mathrm{a}}$, José A. Gomes Neto ${ }^{\mathrm{a}, *}$, George L. Donati ${ }^{\mathrm{b}}$, Bradley T. Jones ${ }^{\mathrm{b}}$ \\ a Department of Analytical Chemistry, São Paulo State University - Unesp, P.O. Box 355, Araraquara, SP 14801-970, Brazil \\ b Department of Chemistry, Wake Forest University, Salem Hall, Box 7486, Winston-Salem, NC 27109, USA
}

\section{A R T I C L E I N F O}

\section{Article history:}

Received 18 October 2016

Accepted 11 March 2017

Available online 12 March 2017

\section{Keywords:}

Standard dilution analysis

Raman spectroscopy

Gasoline analysis

Ethanol determination

\begin{abstract}
A B S T R A C T
This work describes the application of standard dilution analysis (SDA) in Raman spectroscopy, demonstrating the versatility of this new calibration method. A flow system (FA) was developed for ethanol determination in gasoline employing liquid-liquid extraction (LLE) and acetone as the internal standard (IS). Applying LLE eliminated the intense fluorescence background, allowing for ethanol determination using a portable 785-nm-laser Raman system. The SDA-LLE-FA method was applied to commercial gasoline samples and the results were compared with values obtained using the ABNT NBR 13992 reference method. No statistically significant differences were observed for ethanol concentrations determined using the two methods (paired $t$-test at the 95\% confidence level). SDA's accuracy was also evaluated by comparing results from analyses using the same LLE-FA system combined with the traditional calibration methods of matrix matching (MM), standard additions (SA) and internal standardization (IS). Recoveries from spike experiments were in 98.6-104.1\% (SDA-LLE-FA), 94.7171.1\% (ABNT NBR 13992), 106.8-114.1\% (MM-LLE-FA), 103.7-108.4\% (IS-LLE-FA), and 114.7-125.8\% (SA-LLEFA) range. The relative standard deviation (RSD, $n=12,25.5 \% \mathrm{v} / \mathrm{v}^{-1}$ ethanol in gasoline), limits of detection and quantification calculated for the SDA-LLE-FA method were $2 \%, 0.5 \%$ and $1.8 \%\left(\mathrm{v} / \mathrm{v}^{-1}\right)$, respectively.
\end{abstract}

(C) 2017 Elsevier B.V. All rights reserved.

\section{Introduction}

Ethyl alcohol produced from agricultural feedstocks (e.g., corn, wheat, barley, sugar cane) is a renewable, alternative energy source, which is often used as biofuel [1]. Hydrous ethanol is commonly used in ethanol-only and flex-fuel vehicles, while anhydrous ethanol is an important additive for gasoline-powered vehicles [1,2]. Brazil is one of the world's largest producers and consumers of ethanol fuel, with a production of 30,68 billion liters projected to 2016 [3]. The Brazilian National Agency of Petroleum, Natural Gas and Biofuels (ANP, Brazilian Ministry of Mines and Energy) regulates the maximum content of ethanol allowed in commercial gasoline (ethanol/gasoline blends) as $27 \%(\mathrm{v} /$ v) [4]. The reference methods D5501, from the American Society for Testing and Materials (ASTM, USA), and NBR 13992, from the Brazilian Association Technical Standard (ABNT, Brazil), are the official methods recommended by the ANP for ethanol determination in gasoline $[5,6]$. D5501 is based on gas chromatography, while NBR 13992 relies on liquid-liquid extraction. The latter is simple, but it requires large amounts of sample, manual handling, and is time-consuming. The former allows

\footnotetext{
* Corresponding author.

E-mail address: anchieta@iq.unesp.br (J.A. Gomes Neto).
}

for higher sample throughput, but involves higher initial investment (instrument acquisition) and higher running costs.

Raman spectroscopy is a very interesting alternative for applications in fuel analysis. It is non-destructive, potentially portable, requires no sample preparation, and is capable of furnishing compound-specific information $[7,8]$. On the other hand, Raman spectroscopy is plagued by intense background fluorescence signals. In fuel analysis, for example, many organic molecules in the matrix fluoresce, which results in low precision and low sensitivity even for some 785-nm-laser Raman systems [9]. The reduction of large measurement errors due to fluorescence of gasoline was obtained by cooling the spectrometer to $-20^{\circ} \mathrm{C}$ with thermoelectric cooler [8]. However, systems without this accessory must evaluate strategies to reduce that dark-current and improve precision and sensitivity.

The recently proposed SDA method [10] combines the principles of internal standardization and standard additions calibration. It has been successfully used to determine a wide range of analytes by spectrophotometry [10] flame atomic emission spectrometry [11], inductively coupled plasma optical emission spectrometry [10,12], microwave induced plasma optical emission spectrometry [13], and inductively couple plasma mass spectrometry [14]. Because it is based on a matrix-matching, two-solution calibration strategy, SDA can significantly improve sample throughput and accuracy. Additional details on 
SDA's experimental procedures and mathematical basis can be found elsewhere $[9,12]$.

In the current work, we combine liquid-liquid extraction (LLE), flow analysis (FA), and standard dilution analysis (SDA) to overcome the limitations associated with Raman spectroscopy. Considering that ( $i$ ) aqueous extraction of ethanol from gasoline may be effective at minimizing or even eliminating background fluorescence in Raman determinations; (ii) FA systems are excellent to manage solutions and are highly compatible with LLE and SDA; and (iii) SDA can significantly improve accuracy and sample throughput, we investigate the efficiency of a method based on LLE, FA and SDA to determine ethanol in commercial gasoline samples by Raman spectroscopy. Results from the SDA-LLE-FA method are compared with ethanol values obtained with both the official NBR 13992 reference method (ABNT, Brazil), and from analyses using the same LLE-FA system employing the traditional calibration methods of matrix matching (MM), standard additions (SA) and internal standardization (IS).

\section{Materials and methods}

\subsection{Reagents, analytical solutions and samples}

High purity distilled-deionized water obtained from a Millipore Rios $5 \circledR$ reverse osmosis system and a Millipore Milli- ${ }^{\mathrm{TM}}$ Academic ${ }^{\circledR}$ deionizer system (resistivity $18.2 \mathrm{M} \Omega \mathrm{cm}$, Millipore, Bedford, MA, USA) was used to prepare SDA standards and as LLE solvent. Ethanol-free gasoline was obtained by multiple consecutive ethanol extractions using water. Ethanol 99.8\% v/v purity (Panreac, Barcelona, Spain), and ethanol-free gasoline were used for preparing analytical solutions. Acetone $99.9 \% \mathrm{v} /$ v purity (JT Baker, Phillipsburg, USA) was used as internal standard.

Five gasoline samples were purchased in different gas stations in Araraquara, SP, Brazil. All samples were stored in amber glass flasks, which were kept at approximately $5{ }^{\circ} \mathrm{C}$ in a refrigerator until analysis.

\subsection{Instrumentation}

All measurements were carried out using a BWS 415-785H iRaman® spectrometer (B\&W TEK, Newark, NJ, USA) equipped with a fiber optic probe and a BAC 160 Raman flow cell adapted to contain a 2-mL inner volume. A 2048-pixel, thermoelectric-cooled charge-coupled device (CCD) detector, and a $785 \mathrm{~nm}$ laser operated at $80 \%$ maximum output power $\left(350 \mathrm{~mW}\right.$ ) complete the $3.5-\mathrm{cm}^{-1}$ resolution system. Raman spectra were collected in the $175-2700 \mathrm{~cm}^{-1}$ region using a 10 -s integration time. Peak areas were used as analytical signals and calculated by integrating the Raman shifts in the $840-910 \mathrm{~cm}^{-1}$ (C-C stretching), and $756-826 \mathrm{~cm}^{-1}(\mathrm{C}-\mathrm{C}-\mathrm{C}$ stretching) ranges for ethanol and acetone, respectively.

The SDA-LLE-FA system (Fig. 1) comprised an IPC-8 peristaltic pump (Ismatec, Zurich, Switzerland), Tygon ${ }^{\circledR}$ and Tygon MHLL ${ }^{\circledR}$ pumping tubes, a liquid-liquid separator with a PTFE membrane, a Raman spectrometer, polyethylene tubing (i.d. $0.8 \mathrm{~mm}$ ), mixing coils and accessories.

\subsection{Analytical procedure}

The influence of flow rates on extracting conditions was evaluated by increasing the rotation speed of the peristaltic pump to obtain 0.5 , $1.0,1.5,2.0,2.5$ and $3.0 \mathrm{~mL} \mathrm{~min}^{-1}$ flow rates. The influence of the length of coils $B_{1}$ and $B_{2}$, and the gasoline/extracting solvent flow rate ratio on extraction conditions were also evaluated. $B_{1}$ and $B_{2}$ lengths were varied from 50 to $500 \mathrm{~cm}$. Sample and standards flow rates were fixed at $0.5 \mathrm{~mL} \mathrm{~min}^{-1}$, while the extractor solvent flow rate was varied from 0.3 to $1.5 \mathrm{~mL} \mathrm{~min}^{-1}$.

The linear working ranges for ethanol and acetone determination in gasoline were evaluated in the $0-50 \% \mathrm{v} / \mathrm{v}^{-1}$ concentration interval.

The optimized SDA-LLE-FA system was applied to ethanol determination in five gasoline samples. The SDA method requires just a blank and two analytical solutions (A and B) for each sample. Solution A was prepared on-line in the FA system by aspirating the sample (S) and the standard (i.e., an aqueous solution containing $30 \% \mathrm{v} / \mathrm{v}^{-1}$ ethanol and $30 \% \mathrm{v} / \mathrm{v}^{-1}$ acetone, Std) at a $1: 1 \mathrm{v} / \mathrm{v}^{-1}$ flow ratio. Solution B was also prepared on-line by aspirating the blank and the sample $(\mathbf{S})$ also at a $1: 1 \mathrm{v} / \mathrm{v}^{-1}$ flow ratio. These solutions were simultaneously measured in order to obtain a typical SDA curve [10]. The operation of the SDA-LLE-FA system (Fig. 1) comprises three steps: ( $i$ ) water (extractor solvent), blank (water) and ethanol-free gasoline are continuously aspirated until a baseline signal is defined ( $\mathrm{Ca} .15 \mathrm{~s}$ ); (ii) the blank is replaced with Std $\left(30 \% \mathrm{v} / \mathrm{v}^{-1}\right.$ ethanol $+30 \% \mathrm{v} / \mathrm{v}^{-1}$ acetone), the ethanol-free gasoline is replaced with $\mathbf{S}$ and the resulting heterogeneous mixture passes through the liquid-liquid separator, the ethanolenriched water phase flows towards the flow cell, and a typical steady-state signal is recorded; (iii) the Std solution is replaced with the blank, and a concentration gradient is generated, generating then a typical SDA calibration curve shown in Fig. 2; a new cycle can then start by aspirating the next gasoline sample. The SDA plots are constructed by using the ethanol/acetone peak area ratio (using points within the SDA region) on the $y$-axis versus $1 /$ [acetone] on the $x$-axis [10]. Ethanol concentration in the sample $\left(C^{\mathrm{sam}}\right)$ is calculated by $\mathrm{C}^{\mathrm{sam}}$ $=($ slope $/$ intercept $) \times\left(C_{\text {std }} / C_{\mathrm{IS}}\right)$, where $\mathrm{C}_{\text {std }}$ and $\mathrm{C}_{\mathrm{IS}}$ are concentrations of standard ( $30 \% \mathrm{v} / \mathrm{v}$ ethanol) and internal standard (30\% v/v acetone), respectively.

The accuracy was evaluated by comparing results from the SDA-LLEFA method with values obtained using the ABNT NBR 13992 reference method [5]. For the ABNT NBR 13992 procedure, $50 \mathrm{~mL}$ of gasoline are mixed with $50 \mathrm{~mL}$ of a $10 \% \mathrm{mv}^{-1} \mathrm{NaCl}$ aqueous solution in a $100-\mathrm{mL}$ graduated cylinder. The mixture is then shaken by inverting the graduate cylinder 10 times. After a 10-min waiting time, ethanol migrates from the gasoline sample to the higher-polarity $\mathrm{NaCl}$ solution. The

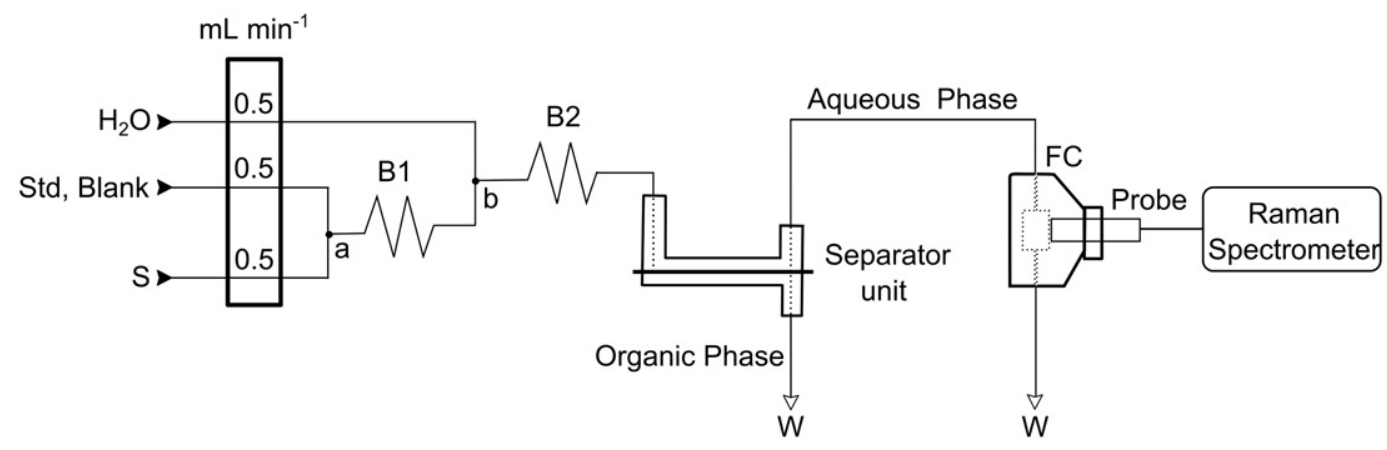

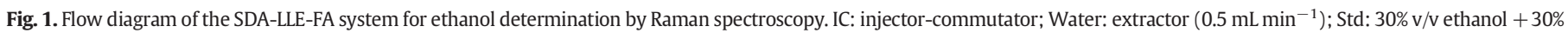
$\mathrm{v} / \mathrm{v}$ acetone solution $\left(0.5 \mathrm{~mL} \mathrm{~min}^{-1}\right)$; blank: water; S: sample $\left(0.5 \mathrm{~mL} \mathrm{~min}^{-1}\right)$; $\mathrm{B}_{1}, \mathrm{~B}_{2}$ : mixing coils ( $500 \mathrm{~mm} \times 0.8 \mathrm{~mm}$ i.d.); W: wastes; a, b: confluent points; FC: flow cell. 


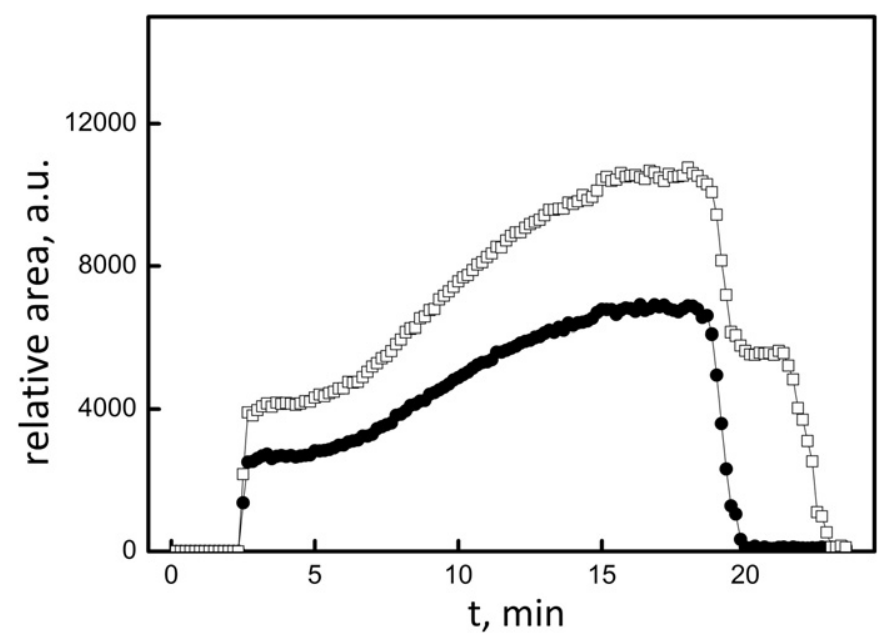

Fig. 2. Typical transient signals for ethanol and acetone simultaneously measured by the SDA-LLE-FA system. $t_{1}, t_{2} t_{3}$ and $t_{4}$ represent the times comprising sequential aspiration of water, Solution A, Solution B and blank, respectively.

ethanol content in gasoline is calculated by determining the aqueous solution volume increase and comparing that difference with the original $50 \mathrm{~mL}$ gasoline volume [5]. Accuracy was also evaluated by addition and recovery experiments using gasoline samples spiked with $25 \% \mathrm{v} / \mathrm{v}^{-1}$ ethanol, or with $15 \% \mathrm{v} / \mathrm{v}^{-1}$ ethanol plus $10 \% \mathrm{v} / \mathrm{v}^{-1}$ methanol.

The performance of the proposed procedure was also evaluated by using the same LLE-FA system in combination with MM, IS and SA (Fig. 3). In this case, the operation of the flow system is generally similar to that depicted in Fig. 1. For the MM calibration, blanks, standards $(0,5$, $10,15,20,25$ and $30 \% \mathrm{v} / \mathrm{v}^{-1}$ ethanol in free-ethanol gasoline) and samples were processed sequentially. Peak areas within the $840-910 \mathrm{~cm}^{-1}$ range $v s$. ethanol concentration were used to build the analytical calibration curve. For IS calibration, blanks, analytical solutions $(5,10,15$, 20,25 and $30 \% \% \mathrm{v} / \mathrm{v}^{-1}$ ethanol in free-ethanol gasoline), and samples were spiked with $17 \% \mathrm{v} / \mathrm{v}^{-1}$ acetone, and processed sequentially in the flow system. The analytical calibration curve was built by plotting peak area of ethanol $\left(840-910 \mathrm{~cm}^{-1}\right) /$ peak area of acetone (756$826 \mathrm{~cm}^{-1}$ ) vs. ethanol concentration. For SA calibration, samples were spiked with $0,5,10,12$ and $15 \% \mathrm{v} / \mathrm{v}^{-1}$ ethanol, and processed sequentially in the flow system; peak area of ethanol within $840-910 \mathrm{~cm}^{-1}$ region vs. ethanol concentration were used to build the analytical calibration curve.

Five Raman spectra were successive collected after aspirating the sample, with integration times of 8, 8 and 15 min for MM, SA and IS, respectively.

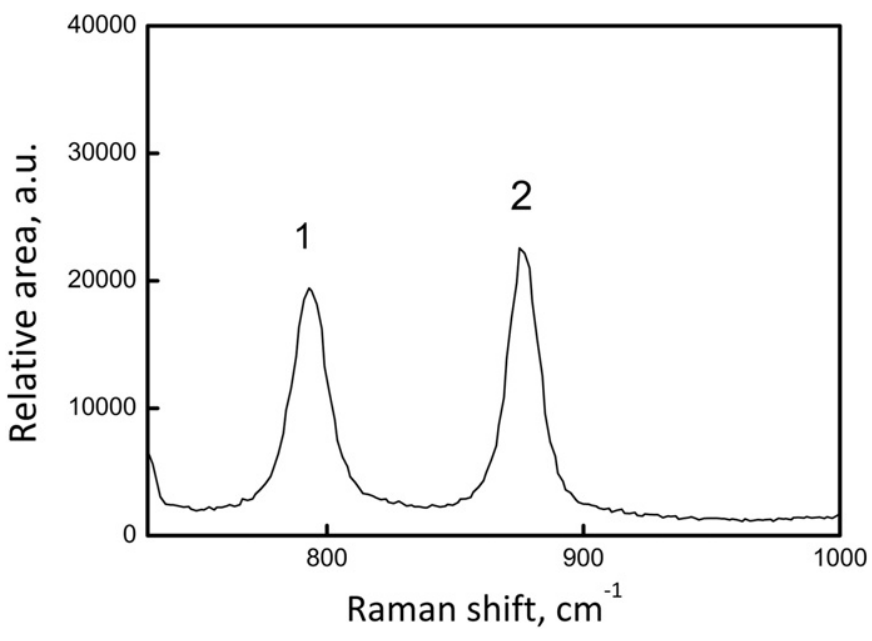

Fig. 4. Raman spectra of a $50 \%\left(\mathrm{v} / \mathrm{v}^{-1}\right)$ ethanol plus $50 \%\left(\mathrm{v} / \mathrm{v}^{-1}\right)$ acetone solution obtained with a laser operated at $80 \%$ maximum output power and a 10 -s integration time. Raman shift in the $840-910 \mathrm{~cm}^{-1}$ (C-C stretching) and 756-826 $\mathrm{cm}^{-1}$ (C-C-C stretching) regions corresponding to ethanol and acetone, respectively.

\section{Results and discussion}

\subsection{Optimization of the LLE-FA system}

The original BAC 160 Raman flow cell was slightly modified to allow its connection with smaller diameter tubing ( $\mathrm{ca} .0 .8 \mathrm{~mm}$ ) commonly employed in flow systems. Screws on both sides of the flow cell, which are used for inlet and outlet solutions (Fig. S1a), were replaced with homemade Teflon screws (Fig. S1b) designed to be suitable for $0.8 \mathrm{~mm}$ (i.d.) polyethylene tubing. Considering its shape and size (Fig. S1c), the inner volume of flow cell ( $c a .2 .0 \mathrm{~mL}$ ) was used as a diluting chamber, which was essential to generating the concentration gradients required for SDA.

The first experiments evaluated the influence of total flow rates on the precision of Raman spectroscopy measurements $(n=5)$. A $20 \% \mathrm{v}$ / $\mathrm{v}^{-1}$ ethanol solution was used in this case, and experiments were carried out with the system depicted in Fig. 1, but without the separator unit (SU). When total flow rate was varied from 0.5 to $3.0 \mathrm{~mL} \mathrm{~min}^{-1}$, peak areas increased almost $5 \%$, and the relative standard deviation changed from 0.6 to $1.6 \%$. Considering that $(i)$ high flow rates increase both the hydrodynamic pressure of the system and the possibility of leakages, (ii) sensitivity was not a critical parameter, and (iii) relative good precision was obtained for all flow rates evaluated, a total flow rate of $1.5 \mathrm{~mL} \mathrm{~min}{ }^{-1}$ was selected for the following studies. The SDA

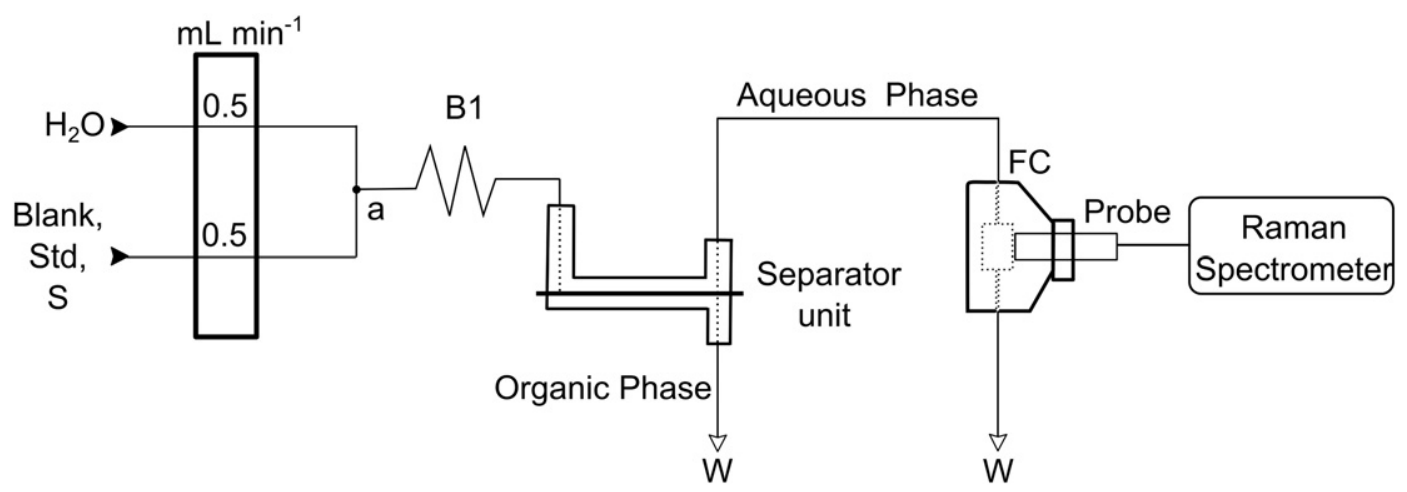

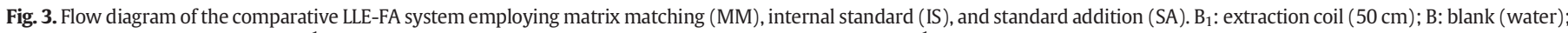

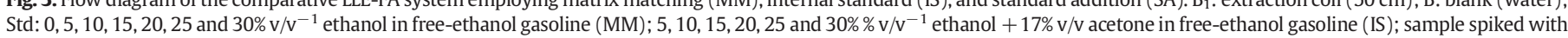
$0,5,10,12$ and $15 \% \mathrm{v} / \mathrm{v}$ ethanol (SA); S: sample; W: waste; and FC: flow cell. 
Table 1

Results (mean \pm standard deviation, $\% \mathrm{v} / \mathrm{v}^{-1}, n=3$ ) for ethanol determination in gasoline by SDA-LLE-FA, by the ABNT NBR 13992 reference method, and by the same LLE-FA system combined with matrix matching (MM), internal standardization (IS) and standard additions (SA) calibrations.

\begin{tabular}{llllll}
\hline Sample & SDA & ABNT NBR & MM & IS & SA \\
\hline 1 & $27.2 \pm 0.2$ & $26.3 \pm 1.2$ & $27.9 \pm 0.3$ & $27.5 \pm 0.2$ & $32.5 \pm 2.0$ \\
2 & $26.0 \pm 0.2$ & $25.7 \pm 1.2$ & $28.2 \pm 0.1$ & $26.9 \pm 0.2$ & $32.6 \pm 0.5$ \\
3 & $25.5 \pm 0.5$ & $25.7 \pm 2.3$ & $28.3 \pm 0.2$ & $27.0 \pm 0.4$ & $34.3 \pm 0.7$ \\
4 & $26.5 \pm 1.0$ & $25.7 \pm 1.2$ & $26.2 \pm 0.5$ & $26.7 \pm 0.1$ & $33.3 \pm 0.2$ \\
5 & $25.7 \pm 1.1$ & $25.7 \pm 1.2$ & $28.7 \pm 0.2$ & $26.6 \pm 0.2$ & $33.6 \pm 1.2$ \\
\hline
\end{tabular}

method requires a 1:1 $\left(\mathrm{v} / \mathrm{v}^{-1}\right)$ dilution between standard (analyte plus IS) and sample solutions (Solution $\mathbf{A}$ ), as well as between blank and sample solutions (Solution B). Therefore, the Std/blank and sample flow rates were identical.

After reconnecting SU to the flow system (Fig. 1), the water/gasoline flow ratio was optimized. Sample and standard flow rates were fixed at $0.5 \mathrm{~mL} \mathrm{~min}^{-1}$, while the water flow rate was varied from 0.3 to $1.5 \mathrm{~mL} \mathrm{~min}^{-1}$. It was observed that as water flow rate increases, so does ethanol peak area, until maximum signal is attained at $0.5 \mathrm{~mL} \mathrm{~min}^{-1}$, corresponding to the maximum extraction efficiency. On the other hand, analytical signals continuously dropped at higher flow rates, with a 4-fold signal reduction in the $0.5-1.5 \mathrm{~mL} \mathrm{~min}^{-1}$ range, due to dilution of ethanol in the aqueous phase.

The influence of mixing coils lengths on the extraction efficiency was also evaluated. No significant effect on analytical signals was observed for coils in the 50-500 cm range, so 50-cm extraction coils were selected for further studies.

The extraction efficiency of the LLE-FA system was evaluated by comparing the ethanol content in a gasoline sample before and after being processed in the flow system. In both cases, the original sample and the organic phase (waste) were analyzed using the ABNT NBR 13992 method. For a gasoline sample containing $25.7 \%\left(\mathrm{v} / \mathrm{v}^{-1}\right)$ ethanol, the extraction efficiency was typically $97 \%$.

Acetone, acetonitrile [15], isopropyl alcohol and methanol were evaluated as potential internal standards for ethanol in SDA determinations. Acetone was chosen as internal standard after considering the similar densities (ethanol: $0.7893 \mathrm{~g} \mathrm{~cm}^{-3}$; acetone: $0.7845 \mathrm{~g} \mathrm{~cm}^{-3}$ ) and partition coefficients (ethanol: -0.31 ; acetone: -0.24 ) [16]. In addition, Raman spectra of acetone and ethanol do not overlap (Fig. 4). The linear working ranges for ethanol and acetone were evaluated using the optimized LLE-FA system. A linear relationship between analytical signals and concentrations were observed within $1-40 \%$, and $1-50 \% \mathrm{v} /$ $\mathrm{v}^{-1}$ for ethanol and acetone, respectively.

\subsection{Ethanol determination}

The SDA-LLE-FA method was applied to ethanol determination in five gasoline samples. For comparison purposes, samples were also analyzed by the ABNT NBR 13992 reference method, and by the same LLEFA system employing the MM, SA and IS calibration methods. Results are shown in Table 1 . All ethanol concentration values determined by SDA-LLE-FA method (25.5-27.2\%) were in agreement, at $95 \%$

Table 2

Recoveries (in $\%, n=3$ ) expressed as mean \pm standard deviation for a gasoline sample spiked with $25 \% \mathrm{v} / \mathrm{v}^{-1}$ ethanol analyzed by SDA-LLE-FA, by the ABNT NBR 13992 reference method, and by the same LLE-FA system combined with matrix matching (MM), internal standardization (IS) and standard additions (SA) calibrations.

\begin{tabular}{llllll}
\hline Sample & SDA & ABNT NBR & MM & IS & SA \\
\hline 1 & $99.8 \pm 2.7$ & $97.3 \pm 4.6$ & $106.8 \pm 0.5$ & $105.5 \pm 0.5$ & $123.7 \pm 2.6$ \\
2 & $101.4 \pm 2.9$ & $94.7 \pm 9.2$ & $108.0 \pm 0.8$ & $106.7 \pm 0.8$ & $118.4 \pm 6.9$ \\
3 & $98.9 \pm 2.7$ & $97.3 \pm 4.6$ & $111.9 \pm 2.9$ & $106.8 \pm 0.7$ & $122.8 \pm 2.9$ \\
4 & $98.6 \pm 4.6$ & $94.7 \pm 4.6$ & $111.2 \pm 0.5$ & $106.6 \pm 0.1$ & $120.9 \pm 7.0$ \\
5 & $100.4 \pm 2.6$ & $94.7 \pm 9.2$ & $110.4 \pm 2.0$ & $105.8 \pm 1.2$ & $125.8 \pm 0.9$ \\
\hline
\end{tabular}

Table 3

Recoveries (in $\%, n=3$ ) expressed as mean \pm standard deviation for a gasoline sample spiked with $15 \%\left(\mathrm{v} / \mathrm{v}^{-1}\right)$ of ethanol plus $10 \%\left(\mathrm{v} / \mathrm{v}^{-1}\right)$ methanol analyzed by SDA-LLE-FA, by the ABNT NBR 13992 reference method, and by the same LLE-FA system combined with matrix matching (MM), internal standardization (IS) and standard additions (SA) calibrations.

\begin{tabular}{llllll}
\hline Sample & SDA & ABNT NBR & MM & IS & SA \\
\hline 1 & $99.1 \pm 2.9$ & $157.8 \pm 7.7$ & $111.7 \pm 3.7$ & $105.9 \pm 2.8$ & $116.7 \pm 3.7$ \\
2 & $103.9 \pm 2.8$ & $157.8 \pm 7.7$ & $107.2 \pm 3.9$ & $103.7 \pm 3.0$ & $120.7 \pm 10.7$ \\
3 & $103.0 \pm 1.5$ & $162.2 \pm 7.7$ & $113.0 \pm 7.6$ & $105.3 \pm 1.5$ & $114.7 \pm 4.2$ \\
4 & $104.1 \pm 2.8$ & $157.8 \pm 7.7$ & $114.1 \pm 3.4$ & $107.5 \pm 0.5$ & $121.5 \pm 3.5$ \\
5 & $103.7 \pm 2.4$ & $171.1 \pm 7.7$ & $110.2 \pm 1.3$ & $108.4 \pm 1.1$ & $116.9 \pm 6.0$ \\
\hline
\end{tabular}

confidence level (paired $t$-test), with those obtained by the ABNT NBR reference method (25.7-26.3\%). On the other hand, while most results for MM and IS calibration (26.2-28.3, and 26.6-27.5\%, respectively) were in agreement with ABNT NBR values, concentrations found with the SA calibration (32.5-34.3\%) were systematically higher by a factor of approximately 1.2. This may be explained by the different dilution factors occurring among standards, which directly affect both slope and intercept. These findings reinforce the effectiveness of combining matrix matching and internal standardization in SDA determinations.

For a gasoline sample containing $25.5 \%\left(\mathrm{v} / \mathrm{v}^{-1}\right)$ ethanol analyzed 12 successive times by SDA-LLE-FA, the relative standard deviation (RSD) was calculated as $2 \%$. Considering all the other samples, analyzed in triplicate, the calculated RSDs were 0.7-4.3\% (SDA-LLE-FA), 4.6-8.9\% (ABNT NBR 13992), 0.4-1.7\% (MM-LLE-FA), 0.5-1.5\% (IS-LLE-FA) and 0.6-6.2\% (SA-LLE-FA).

The performance of the SDA-LLE-FA method was also evaluated by addition and recovery experiments using a gasoline sample spiked with $25 \% \mathrm{v} / \mathrm{v}^{-1}$ ethanol (Table 2). Recoveries were in the ranges of 98.6-101.4\% (SDA-LLE-FA), 94.7-97.3\% (ABNT NBR 13992), 106.8$111.9 \%$ (MM-LLE-FA), 105.5-106.8\% (IS-LLE-FA), and 118.4-125.8\% (SA-LLE-FA). The influence of methanol (usually present in gasoline) on ethanol recoveries was also evaluated. For a gasoline sample spiked with $15 \% \mathrm{v} / \mathrm{v}^{-1}$ ethanol plus $10 \% \mathrm{v} / \mathrm{v}^{-1}$ methanol, recoveries (Table 3 ) were 99.1-104.1\% (SDA-LLE-FA), 157.8-171.1\% (ABNT NBR 13992), 107.2-114.1\% (MM-LLE-FA), 103.7-108.4\% (IS-LLE-FA), and 114.7$121.5 \%$ (SA-LLE-FA). These findings reveal an important limitation of the ABNT NBR 13992 reference method, which is associated with selectivity. The limits of detection (LOD) and quantification (LOQ) calculated for the SDA-LLE-FA method were $0.5 \% \mathrm{v} / \mathrm{v}$ and as $1.8 \% \mathrm{v} / \mathrm{v}$ ethanol, which are adequate for quality control of ethanol in gasoline.

\section{Conclusions}

The SDA-LLE-FA method is a simple and efficient alternative for overcoming issues associated with intense fluorescence background in determinations using portable 785-nm-laser Raman systems. The method described here has showed good precision and accuracy for ethanol determination in commercial gasoline samples. The SDA strategy presents the advantage of combining the benefits of standard additions and internal standardization, and the convenience of preparing only one standard, while analyzing samples automatically in two steps. The use of a FA system for solution handling is an effective approach to reducing analysis time, sample consumption, residue generation, and to improve precision and sample throughput.

Supplementary data to this article can be found online at http://dx. doi.org/10.1016/j.microc.2017.03.015.

\section{Acknowledgements}

The authors thank the São Paulo Research Foundation - FAPESP for financially supporting this work (Project 2014/12595-1) and for fellowships to F.M.F. (2012/23323-7). The Conselho Nacional de Desenvolvimento Científico e Tecnológico - CNPq is also thanked for 
financially supporting this work (Project 471453/2013-7) and the fellowship granted to J.A.G.N. (303255/2013-7). Support from the Graduate School of Arts and Sciences at Wake Forest University is also greatly appreciated.

\section{References}

[1] P.F. Pereira, M.C. Marra, R.A.A. Munoz, E.M. Richter, Fast batch injection analysis system for on-site determination of ethanol in gasohol and fuel ethanol, Talanta 90 (2012) 99-102.

[2] L.S. Mendes, F.C.C. Oliveira, P.A.Z. Suarez, J.C. Rubim, Determination of ethanol in fuel ethanol and beverages by Fourier transform (FT)-near infrared and FT-Raman spectrometries, Anal. Chim. Acta 493 (2003) 219-231.

[3] S. Barros, Brazil: Biofuels Annual, USDA Foreign Agricultural Service, GAIN Report BR15006, August 10Available at http://gain.fas.usda.gov/Recent\%20GAIN\%20Publications/Biofuels\%20Annual_Sao\%20Paulo\%20ATO_Brazil_8-4-2015.pdf 2015 (retrieved Oct. 01, 2016)

[4] ANP - Agência Nacional de Petróleo, Gás Natural e Biocombustíveis -Especificações das gasolina de uso automotivo. Resolução ANP No. 40; Brasília DF; 30.10.2013.

[5] ABNT, Brazilian Association Technical Standard - Motor gasoline - Determinations of Fuel Anydrous Ethylic Alcohol Content. NBR-13992; Rio de Janeiro RJ, 2015.

[6] ASTM - American Society for Testing and Materials, Standard Test Method for Determination of Ethanol and Methanol Content in Fuels Containing Greater Than 20\% Ethanol by Gas Chromatography. ASTM D5501-12; West Conshohocken PA, 2013.

[7] C. Frausto-Reyes, C. Medina-Gutierrez, R. Sato-Berru, L.R. Sahagun, Qualitative study of ethanol content in tequilas by Raman spectroscopy and principal component analysis, Spectrochim. Acta, Part A 61 (2005) 2657-2662.
[8] O. Ye, Q. Xu, Y. Yu, R. Ou, Z. Fang, Rapid and quantitative detection of ethanol proportion in ethanol-gasoline mixtures by Raman spectroscopy, Opt. Commun. 282 (2009) 3785-3788.

[9] S.J. Choquette, S.N. Chesler, D.L. Duewer, S. Wang, T.C. O'Haver, Identification and quantitation of oxygenates in gasoline ampules using Fourier transform near-infrared and Fourier transform Raman spectroscopy, Anal. Chem. 68 (1996) 3525-3533.

[10] W.B. Jones, G.L. Donati, C.P. Calloway Jr., B.T. Jones, Standard dilution analysis, Anal. Chem. 87 (2015) 2321-2327.

[11] F.M. Fortunato, M.A. Bechlin, J.A. Gomes Neto, A. Virgilio, G.L. Donati, B.T. Jones, Standard dilution analysis in flow system: sodium determination by flame atomic emission spectrometry, Microchem. J. 124 (2016) 662-667.

[12] A. Virgilio, D. Schiavo, J.A. Nobrega, G.L. Donati, Evaluation of standard dilution analysis (SDA) of beverages and foodstuffs by ICP OES, J. Anal. At. Spectrom. 31 (2016) 1216-1222.

[13] D.A. Goncalves, T. McSweeney, M.C. Santos, B.T. Jones, G.L. Donati, Standard dilution analysis of beverages by microwave-induced plasma optical emission spectrometry, Anal. Chim. Acta 909 (2016) 24-29.

[14] A. Virgilio, D. Schiavo, L.M. Costa, J.A. Nobrega, B.T. Jones, G.L. Donati, Inductively coupled plasma mass spectrometry and standard dilution analysis applied to concentrated acids, Talanta 161 (2016) 826-829.

[15] I.H. Boyaci, H.E. Genis, B. Guven, U. Tamer, N. Alper, A novel method for quantification of ethanol and methanol in distilled alcoholic beverages using Raman spectroscopy, J. Raman Spectrosc. 43 (2012) 1171-1176.

[16] D.R. Lide (Ed.), CRC Handbook of Chemistry and Physics, $88^{\text {th }}$ ed.CRC Press, Boca Raton, 2008. 